\title{
CRIAÇÃO DE NOVOS MUNICÍPIOS: UMA REVISÃO SOBRE A LITERATURA PRESENTE NO PORTAL DE PERIÓDICOS DA COORDENAÇÃO DE APERFEIÇOAMENTO DE PESSOAL DE NÍVEL SUPERIOR (CAPES)
}

Nathália Bonow ${ }^{1}$

Robinson Santos Pinheiro ${ }^{2}$

Resumo: Com a promulgação da Constituição Federal de 1988, houve uma notória fragmentação do território brasileiro a partir da criação de milhares de novos municípios. Diante disso, busca-se realizar uma revisão de literatura na plataforma Portal de Periódicos da CAPES, utilizando a palavra-chave "criação de municípios", para compreender os fatores que levaram a esta acelerada fragmentação. Dessa forma, percebe-se que a criação de novas municipalidades ocorreu de maneira semelhante em vários municípios do Brasil e encontra-se atrelada a diversos fatores, dentre eles: busca pela autonomia municipal da localidade e fatores políticos, econômicos e jurídicos.

Palavras-chave: Criação de municípios. Constituição Federal de 1988. Fragmentação territorial.

\section{CREATION OF NEW MUNICIPALITIES: A REVIEW ABOUT THE LITERATURE PRESENT IN THE PORTAL OF PERIODICALS FOR THE COORDINATION OF IMPROVEMENT OF STAFF OF HIGHER LEVEL (CAPES)}

\begin{abstract}
With the enactment of the Federal Constitution of 1988, a prominent fragmentation of Brazilian territory started after the creation of millions of new municipalities. Thus, it is aimed to perform a literature review in the CAPES Portal of Journal using the keyword "creation of municipalities", to understand the factors that led to this accelerated fragmentation. Therefore, it is possible to perceive that the creation of new municipalities happened similarly in several municipalities in Brazil and occurs due to various factors, such as: the search for the locality's municipal autonomy and political, economic and legal factors.

Keywords: Creation of municipalities. Federal Constitution of 1988. Territorial fragmentation.

\section{CREACIÓN DE NUEVOS MUNICIPIOS: UNA REVISIÓN DE LA LITERATURA PRESENTE EN EL PORTAL DE PERIÓDICOS DE LA COORDINACIÓN DE PERFECCIONAMIENTO DE PERSONAL DE NIVEL SUPERIOR (CAPES)}

Resumen: Con la promulgación de la Constitución Federal de 1988, ocurrió una notoria fragmentación del territorio brasileño a partir de la creación de miles de nuevos municipios. Delante a esto, buscamos realizar una revisión de la literatura en el Portal de Periódicos de CAPES, utilizando la palabra clave "creación de municípios" a fin de comprender los factores que llevaron a esta acelerada fragmentación. Por lo tanto, se nota que la creación de nuevos municipios se ha producido de manera similar en varios municipios de Brasil e está vinculada a

\footnotetext{
${ }^{1}$ Universidade Federal de Pelotas, Programa de Pós-Graduação em Geografia, Pelotas/RS, Brasil, nathaliabonow@gmail.com, https://orcid.org/0000-0001-6207-7407.

2 Universidade Federal de Pelotas, Programa de Pós-Graduação em Geografia, Pelotas/RS, Brasil, robinson22pinheiro@yahoo.com.br, https://orcid.org/0000-0003-1763-4344.
} 
diversos factores, entre ellos: la búsqueda de la autonomía municipal de la localidade e factores políticos, economicos y legal.

Palabras clave: Creación de municípios. Constitución Federal de 1988. Fragmentación territorial.

\section{Introdução}

Segundo Castro (2005), município é o poder local, parte integrante da Federação, onde exercemos a nossa cidadania, direitos, deveres e ao qual recorremos para sanar nossas garantias como cidadãos. Além disso, Castro (2005, p. 135), destaca que o município é: “[...] território político por excelência, e constitui um distrito eleitoral formal para vereadores e prefeitos e informal para todas as outras eleições".

No Brasil, contemporaneamente, o município é um ente federado autônomo, regido por uma lei orgânica, sendo a Prefeitura e a Câmara Municipal os órgãos políticos-administrativos desse ente federativo. Mas segundo Matsumoto, Franchini e Mauad (2012 apud MEIRELLES, 2003, p. 45):

[...] o conceito de município flutuou no Brasil ao sabor dos regimes, que ora alargavam, ora comprimiam suas franquias, dando-Ihes liberdade política e financeira ou reduzindo-o à categoria de corporação meramente administrativa, embora todas as Constituições do Brasil inscrevessem em seus textos a tão aspirada autonomia municipal [...]

Ainda com base em Matsumoto, Franchini e Mauad (ibid., p. 45), a partir da Constituição de 1946, o município passa a ter de fato uma autonomia administrativa, sendo esse um dos fatores de sua importância no ordenamento territorial brasileiro. Ou seja, é função do poder municipal desfrutar de sua autonomia para, entre outras funções, atender as demandas da população e representar a localidade nas demais esferas do poder.

Nessa perspectiva, Montoro (1976, p. 30), ao tratar sobre a quantidade de municípios brasileiros e a possibilidade de extinção destes, coloca que:

A proximidade do governo local é necessária para o desenvolvimento de qualquer comunidade. Não é sem motivo que um dos primeiros movimentos que surgem espontaneamente com o desenvolvimento de uma região é a campanha por sua emancipação política. Isto ocorre porque sabem os moradores da região que a presença de um governo local próximo se constitui num eficiente instrumento de progresso. Se este não puder ser conseguido pela atuação dos novos governantes municipais, com recursos da própria comunidade, a existência de um governo local constituído é muito importante para reivindicar melhoramentos aos governos estadual e federal. 
A partir da Constituição Federal de 1988, os municípios foram elevados a $3^{\circ}$ membro da Federação, receberam uma autonomia ainda maior e foram conferidos atributos de criação, fusão e desmembramento de municípios com poucas limitações. Assim, se favoreceu a criação de novas municipalidades, levando a um novo boom de criação de municípios ${ }^{3}$.

$\mathrm{Na}$ Constituição Federal de 1988, foram instituídos novos critérios de criação de municípios, diferentes dos estabelecidos anteriormente pela Constituição de 1846, ao qual forma substituídos pelos Artigos 2 e 3 da Lei Complementar no 1/1967, instaurada após a Constituição de 1967, no período do regime civil-militar brasileiro. Dentre as normas estabelecidas na Lei Complementar 1/1967, aqui se destaca: população superior a 10.000 habitantes e não inferior a cinco milésimos da população do Estado; eleitorado mínimo de $10 \%$ da população; centro urbano já constituído com um mínimo de 200 casas; uma arrecadação no último exercício correspondente, pelo menos, a cinco milésimos da receita estadual de impostos; e plebiscito para consulta à população da área territorial interessada (BRASIL, 1967).

Dessa forma, a redação primordial do parágrafo 4ํㅡㄹ do Art. 18 da Constituição Federal de 1988 se tornou a base para criação de novas municipalidades. Neste parágrafo estava instituído que os parâmetros para a criação, fusão e desmembramento de municípios deveriam ser estabelecidos pelos governos estaduais e que era preciso uma consulta prévia, por meio de plebiscito a população da localidade que buscava se desmembrar, ou seja, a população diretamente interessada. No Rio Grande do Sul, a título de exemplo, esses parâmetros de criação foram determinados pelas Leis Complementares oㅜ 9.070, de 1990 e oㅜ 9.089, também de 1990.

Vale destacar que após a instalação de vários municípios com base no parágrafo $4^{\circ}$ do Art. 18, essa norma passou por alterações através da promulgação da Ementa Constitucional no 15, de 1996, que levou a desaceleração da criação de novas municipalidades, pois estabeleceu critérios emancipacionistas mais rígidos, conforme destacam Souza e Cigolini (2019, p. 46):

Embora a Emenda Constitucional 15/1996 tenha mantido sob a responsabilidade dos estados a elaboração das leis referentes aos desmembramentos, criou regras como EVM (Estudo de Viabilidade Municipal) e exigiu que o necessário plebiscito fosse estendido a toda população, inclusive a do município de origem, e não apenas à população do distrito envolvido no processo. A Emenda passou a ser válida após sua

\footnotetext{
${ }^{3}$ A primeira explosão na criação de novas municipalidades ocorreu no Período Democrático, entre os anos 1950-1964. (FERRARI, 2016, p. 57).
} 
publicação, porém seria necessária uma Lei Complementar para regulamentar as exigências contidas na mesma [...]

Assim, o texto inicial do parágrafo $4^{\circ}$ do Art. 18 da Constituição Federal de 1988, juntamente com a criação das leis estaduais que estabelecem os critérios de criação de municípios, entra em cena a ação das pessoas que desejavam de emancipar uma localidade por questões políticas, econômicas, sociais, pessoais, dentre outros. Essas pessoas seriam, principalmente, os políticos locais e a população em geral residente na localidade que buscava pela emancipação e que participavam ativamente do processo, reunindo documentos e realizando $o$ levantamento do número de casas, comércios, escolas e demais dados da localidade. Posteriormente, esse compilado de informações era enviado para a Assembleia Legislativa, que mediante a análise dos documentos, aprovava, ou não, a realização do plebiscito na região. E, assim, principalmente após o envio das informações sobre a região, os políticos em instâncias superiores, como os deputados estaduais, se tornavam nomes importantes para a de criação da municipalidade, pois eles poderiam usar a sua influência na Assembleia Legislativa para que fosse aprovado a realização do plebiscito na localidade.

Sendo assim, se coloca que o município é um território de interesses, que usufrui de certa autonomia e que está envolto por relações de poder e também disputas entre partidos políticos, prefeito e vereadores, população favorável ou contrária a administração e interesses políticos em geral. Do mesmo modo, o município como delimitação territorial governado por representantes eleitos pelo povo, passa a ser uma importante esfera do poder também na questão da visibilidade do local e em relação as questões relacionadas a essa localidade, como o crescimento econômico e o desenvolvimento social.

Mediante a isso, o objetivo dessa revisão de literatura é mapear como pesquisadores estão discutindo a criação de novas municipalidades no Brasil, especificamente no período pós Constituição Federal de 1988, respondendo às perguntas: qual o contexto que promove/estimula a emancipação municipal? E quais são as consequências decorrentes dessa emancipação?

Para isso, foi realizada uma busca nas plataformas Latindex (Sistema Regional de Información en Línea para Revistas Científicas de América Latina, el Caribe, España y Portugal) ${ }^{4}$, SciELO (Scientific Electronic Library Online) ${ }^{5}$ e Portal de Periódicos da Coordenação de Aperfeiçoamento de Pessoal de Nível Superior

\footnotetext{
${ }^{4}$ Link de acesso: https://www.latindex.org./

${ }^{5}$ Link de acesso: https://www.scielo.org/
} 
(CAPES) ${ }^{6}$, a fim de perscrutar sobre a criação de novos municípios no Brasil após a Constituição de 1988.

\section{Metodologia}

Como mencionado, para a escolha dos artigos que compõem essa revisão de literatura, se realizou uma busca nas plataformas Latindex, SciELO e Portal de Periódicos da CAPES. Essa busca foi efetuada por meio da utilização da palavrachave "criação de municípios".

A preferência por essas plataformas de busca, justifica-se devido as mesmas concentrarem a parte mais importante da produção brasileira, atingindo mediante a isso, o objeto da análise desse artigo. Já a escolha do termo de busca, fundamentase por meio da intenção da pesquisa, que trata de analisar o contexto da criação de municípios a partir da jurisdição vigente no período pós Constituição de 1988 . Ou seja, a escolha por esta palavra-chave ocorre, pois, o termo "criação de municípios" se refere à instituição de uma unidade política como um marco legal. Devido a isso, não se utilizou, por exemplo, a palavra "emancipação política", pois esse termo está relacionado a outros fatores mais complexos, como a independência, autonomia da região emancipada, não se relacionando ao marco legal, de fato.

$\mathrm{Na}$ plataforma Latindex, não foram localizados artigos a partir da palavrachave "criação de municípios". Assim, a busca se deu na plataforma SciELO e no Portal de Periódicos da CAPES. Dessa forma, se optou pela escolha do Portal de Periódicos da CAPES pois a procura resultou em uma oferta maior de trabalhos que falassem sobre a criação de novas municipalidades. Além disso, essa plataforma trabalha predominantemente com revistas brasileiras, e como este trabalho analisa a criação de municípios a partir da Constituição da República Federativa do Brasil de 1988, se tornou mais conveniente utilizá-la.

No Portal de Periódicos da CAPES, optou-se pela investigação por meio do campo "pesquisa avançada", onde foram escolhidos, para esta revisão de literatura, trabalhos que tivessem o termo "criação de municípios" no título e que tratassem do período posterior a Constituição Federal de 1988. A escolha desse período de análise se justifica, como dito anteriormente, pelo fato de que a Constituição de 1988 ofereceu um aporte para a criação de novas municipalidades. Além disso, esse foi um dos períodos descentralizadores em relação a criação de novos municípios brasileiros, e o mais recente, pois o outro momento de descentralização ocorreu a

${ }^{6}$ Link de acesso: https://www.periodicos.capes.gov.br/ 
partir da Constituição de 1946, até o início da ditadura civil-militar brasileira, em 1964.

Assim, foram localizados 12 artigos, onde dois desses estavam repetidos, pois ambos foram publicados na mesma revista, mas estavam com indexadores diferentes $^{7}$. Ou seja, esses 12 artigos localizados se tratavam de 10 trabalhos diferentes. Além disso, um desses 10 artigos, não possuía o termo "criação de municípios" no título, sendo eliminado por esse fator. Dessa forma, restaram 9 artigos que versam sobre a criação de municípios pós Constituição de 1988.

Esses artigos, como pode ser visto na tabela 01, foram agrupados em duas categorias: os que falam da criação de municípios no contexto geral brasileiro, ou seja, não falam de municípios ou estados específicos, como Fernandes e Araújo (2015), Cigolini (2012), Nunes (2017) e Tomio (2002); e os que tratam da criação de novas municipalidades em estados específicos, como Alves (2006), Baltar e Baltar (2018) e Cigolini (2001), que tem por foco de análise o estado do Paraná, Silva (2009), que faz uma análise sobre as emancipações no Mato Grosso e Tomio (2005), que fundamenta sua pesquisa sobre as emancipações no Rio Grande do Sul.

Tabela 01 - Categorias de agrupamento dos artigos

\begin{tabular}{|c|c|c|}
\hline $\begin{array}{l}\text { Categoria de } \\
\text { agrupamento }\end{array}$ & Autores & Título do artigo \\
\hline \multirow{12}{*}{$\begin{array}{l}\text { Criação de } \\
\text { municípios - } \\
\text { contexto nacional } \\
\text { (geral) }\end{array}$} & Fernandes e & - A criação de municípios e a \\
\hline & Araújo (2015) & formalização de regiões \\
\hline & & metropolitanas: os desafios da \\
\hline & & coordenação federativa \\
\hline & Cigolini (2012) & - Território e criação de municípios: o \\
\hline & & significado teórico-político da \\
\hline & & compartimentação do espaço \\
\hline & Nunes (2017) & - Criação de municípios no Brasil: \\
\hline & & motivações, vantagens e \\
\hline & & desvantagens \\
\hline & Tomio (2002) & - A criação de Municípios após a \\
\hline & & Constituição de 1988 \\
\hline Criação de & Alves (2006) & $-\mathrm{Opr}$ \\
\hline
\end{tabular}

\footnotetext{
7 Um artigo constava como indexador SciELO e Directory of Open Access Journals (DOAJ), e o outro, o indexador era Cengage Learning, Inc. e Directory of Open Access Journals (DOAJ).
} 
municípios -

casos específicos

estaduais
Baltar e Baltar (2018)

Cigolini (2001)

Silva (2009)

Tomio (2005) municípios no Paraná: as instituições

e a relação entre executivo

- Debatendo a criação de municípios

na contemporaneidade: considerações a partir da urbanização e da participação dos pequenos municípios no Brasil e no

Paraná - Território e fragmentação: análise do processo recente de criação de municípios no Paraná - A criação de municípios no front e a formação da elite do agronegócio: faces do uso do território brasileiro - Federalismo, municípios e decisões legislativas: a criação de municípios no Rio Grande do Sul

Fonte: autores, 2019.

É importante ressaltar a divisão dos artigos nas duas categorias mencionadas acima, justifica-se pelo fato de que no parágrafo $4^{\circ}$ do Art. 18 da Constituição Federal de 1998, está explícito que "A criação, a incorporação, a fusão e o desmembramento de Municípios [...] far-se-ão por lei estadual, obedecidos os requisitos previstos em Lei Complementar estadual” (BRASIL, 1988). Dessa forma, cada estado era independente para elaborar seus critérios de criação, fusão ou desmembramento de municípios, sendo, portanto, os processos emancipacionistas diferentes em cada estado brasileiro. Essas categorias também permearão a divisão do restante desse artigo.

Também, é relevante destacar a existência do artigo "Análise da literatura explicativa sobre o processo contemporâneo da criação de municípios no Brasil" (CIGOLINI, 2017), que possui uma abordagem semelhante ao artigo ora proposto, mas com um compilado mais abrangente de trabalhos sobre a criação de novas municipalidades brasileiras. 


\section{A criação de municípios no Brasil após a Constituição de 1988}

O primeiro grupo de artigos analisados trabalha a criação de municípios brasileiros em escala nacional pós a Constituição Federal de 1988, onde são expostos motivos que favoreceram e/ou estimularam as emancipações. Tratam principalmente das intenções políticas e econômicas da criação de novas municipalidades, além de aspectos demográficos relacionados a criação de municípios pequenos. Além disso, falam da questão da autonomia municipal, do Fundo de Participação dos Municípios (FPM), do caráter emancipacionista descentralizador e da mobilização da população e políticos locais, além dos deputados estaduais, como questões para justificar o boom das emancipações pós 1988.

Dessa forma, este subcapítulo está estruturado em duas partes: primeiramente, busca-se entender o papel dos entes envolvidos no processo emancipacionista, como a ação dos políticos e da população local, dos deputados estaduais e também dos requisitos jurídicos que permeiam a criação de novas municipalidades. No segundo momento, a análise gira em torno da capacidade de gestão dos municípios, baseada nos fatores que serão expostos na primeira parte dessa seção.

Um dos elementos importantes para a compreensão dos fatores de criação de municípios, é a autonomia municipal da qual a área emancipada deveria usufruir, pois é estabelecida já na Constituição de 1946. Segundo Nunes (2017), ao fazer uma caraterização do papel dos municípios no período anterior à Constituição de 1988, cita que os mesmos nem sempre possuíram autonomia e que somente a partir da Carta Magna de 1988, esta autonomia é instituída aos municípios. Ou seja, mesmo sendo estabelecida a autonomia em 1946, ela não ocorria de fato. O episódio que leva à implantação de uma autonomia municipal em 1988 se baseia no Art. 18 da Constituição vigente (BRASIL, 1988), onde está instituído que a organização político-administrativa brasileira abrange a União, os estados, o Distrito Federal e os municípios, sendo esses entes federativos autônomos.

Conforme elenca Cigolini (2012), a autonomia municipal proporciona uma organização interna no município diferenciada, característica daquele território. Assim, a autonomia não é somente econômica, mas também política e social. Isso ocorre pois está instituído na Carta Magna de 1988 que cada município tem a liberdade de arrecadar tributos locais, eleger representantes políticos e, também, 
criar leis sobre o seu território. Com isso, o município passa a ser de certa forma autônomo.

Outro fator que impulsionou a criação de municípios, está fundamentado na questão econômica de repasse das verbas provindas da União. Fernandes e Araújo (2015) citam que é do Governo Federal, por meio do Imposto sobre Circulação de Mercadorias e Serviços de Transporte e Comunicação (ICMS), que provém a maior parte da arrecadação de fundos brasileiros. Do mesmo modo, alegam que grande parte dos municípios dependem do repasse do ICMS e também do Fundo de Participação Municipal (FPM), que também provém da União, além de outras quantias, como o Fundo de Manutenção e Desenvolvimento do Ensino Fundamental e de Valorização do Magistério (FUNDEF), Fundo de Manutenção e Desenvolvimento da Educação Básica e de Valorização dos Profissionais da Educação (FUNDEB) e o Fundo Nacional da Saúde (FNS) para conseguir realizar investimentos nos diversos setores de organização de um município.

Dessas verbas repassadas aos municípios, o FPM é a mais importante, sendo a principal fonte redistributiva de fomento à arrecadação municipal de vários municípios pequenos. Destaca-se que o principal "erro" em relação ao FPM se dá pela má distribuição dessa verba, pois existe atualmente uma base de distribuição dessa quantia, onde o valor repassado a municípios com menos de dois mil habitantes é igual ao repassado aos municípios com 10 mil habitantes, por exemplo, resultando, assim, numa distribuição desigual (FERNANDES e ARAÚJO, 2015).

No que se refere a questão jurídica, o período descentralizador de 1988, ano da promulgação da Constituição Federal, até 1996, quando foi estabelecida a Emenda Constitucional no 15, que estagnou os processos emancipacionistas, também foi um dos fatores aliado ao grande número de novos municípios criados. Isso ocorre devido ao controle das emancipações ter sido passado aos estados, que por meio de leis pouco restritivas, emanciparam vários municípios. Relacionado a isso, se encontra também a questão dos políticos locais e dos deputados estaduais, que interferiam para as emancipações ocorrerem e, com isso, arrecadar votos tanto na nova prefeitura, no caso dos governos locais, quanto na Assembleia Legislativa estadual. Conforme colocam Fernandes e Araújo (2015, p. 299):

Cabe dizer que o boom da década de 1990 ocorreu em um contexto em que se verifica conexão eleitoral nas emancipações municipais, a qual partia das lideranças locais com os deputados estaduais e deles com o Executivo estadual, visando a votos dos eleitores do interior do estado. Assim se explicam as leis complementares estaduais com critérios pouco rígidos para a criação de municípios no final dos anos de 1980 e início dos anos de 1990. 
Fernandes e Araújo (2015) também destacam o papel da União na estagnação da criação de municípios, por meio da Emenda Constitucional nำ 15, de 1996. Nesta Emenda, ficou determinado que a criação de novos municípios se dará a partir de lei estadual, dentro de um período estabelecido por lei complementar federal. Mas desde a promulgação desta Emenda Constitucional até o momento, não foi apresentada nenhuma lei complementar federal que possibilitasse a criação de novos municípios. Ao mesmo tempo, nada foi feito para modificar essa situação. Ou seja, Fernandes e Araújo (2015), colocam que a União ainda não instituiu regras de criação de municípios e que essa situação não pode ser omitida para sempre.

Entrando na segunda parte desse subcapítulo, busca-se trazer um contraponto em relação ao exposto na seção anterior. Voltando a questão da autonomia municipal, Fernandes e Araújo (2015) colocam que esse fator é o principal problema enfrentado pela federação brasileira, pois muitos municípios não possuem capacidade fiscal, financeira e institucional para gerir seu território sem os recursos provindos do governo federal e estadual, e, com isso, ficam dependentes do repasse de verbas.

Dentre os municípios pertencentes a esse grupo, os autores (ibid, 2015) apontam os $45,9 \%$ dos municípios brasileiros que possuem menos de 10 mil habitantes e, assim, possuem condições inferiores para se manter, comparado a municípios com população maior. Mediante a isso, Fernandes e Araújo (2015) colocam que o FPM é o principal capital repassado pela União as municipalidades e se faz muito importante na manutenção de pequenos municípios, pois como a arrecadação dos mesmos resulta num valor baixo, é por meio desse Fundo que o município obtém fôlego para investir em questões sociais gerais.

Portanto, se percebe que a autonomia e a economia se inter-relacionam e que a autonomia só existirá de fato se houver independência econômica por parte do município para gerir a sua demanda. Além disso, a autonomia municipal também está relacionada a questão jurídica de submissão a normas determinadas nas instâncias estadual e federal, que devem ser obedecidas.

Fechando esse subcapítulo, coloca-se também que a autonomia e o repasse de verbas ocasionam um reconhecimento da localidade no contexto estadual e federal, além de promover uma negociação mais efetiva e direta com o legislativo e o executivo para atender as demandas locais. Também, segundo Tomio (2002) e Fernandes e Araújo (2015), os atores por trás desse processo de criação de novos 
municípios, como eleitores, políticos locais e deputados estaduais estavam sempre na busca de vantagens pessoais, como melhorias na infraestrutura da localidade e em políticas sociais, assim como arrecadação de votos.

Dessa forma, dentro da narrativa nacional sobre a criação de municípios, se verificou uma polissemia de motivos/fatores que levaram a fragmentação territorial pós a Constituição Federal de 1988, contudo, cabe destacar a predominância do fator político.

\section{A criação de municípios, em diferentes estados brasileiros, pós 1988}

O segundo grupo de análise trabalha com a questão das criações de municípios em diferentes estados brasileiros. Desses trabalhos, Cigolini (2001), Alves (2006) e Baltar e Baltar (2018) analisam as emancipações no Paraná, Tomio (2005) traz como recorte da sua pesquisa o Rio Grande do Sul e Silva (2009), o Mato Grosso. Por meio desse estudo mais específico por estados, é possível perceber que os processos de emancipação em diferentes entes estaduais são muito semelhantes.

Cigolini (2001), ao fazer um levantamento de documentos dos processos emancipacionistas para buscar compreender quais os motivos da criação dos 81 novos municípios no Paraná pós Constituição de 1988, coloca que encontrou dados referentes a 22 processos e que destes, 13 constavam que o motivo principal da busca pela criação de uma nova municipalidade se justificava pela busca da autonomia econômica da região e, dessa forma, poder gerir e investir em áreas de fato relevantes na localidade. Após a descoberta desse dado, o autor realizou outra busca e conclui que destes 13 municípios, apenas 2 realmente possuíam condições econômicas favoráveis para se sustentarem de forma autônoma.

A partir disso, Cigolini (2001) afirma que vários municípios no Paraná foram criados burlando a legislação estabelecida para a criação de novos municípios, buscando atender, de fato, demandas pessoais ou locais. Ou seja, além dos fatores pouco restritivos impostos para a criação de novos municípios no Paraná, essas questões eram burladas, pois a emancipação das localidades era um meio de trazer benefícios e novas possibilidades mediante o processo de criação de um novo território como meio de controle econômico e de representatividade política.

Cigolini (2001) também vai ao encontro com a perspectiva da pesquisa de Silva (2009), acerca da criação de municípios no front agrícola do Mato Grosso, que destaca que o surgimento de novas municipalidades está relacionado a formação de 
novas elites regionais. Salienta que a localidade onde estava presente a moderna agricultura, devido a inserção do meio técnico-científico-informacional (SANTOS, 2006), caracterizada, principalmente, pelas commodities de soja, necessitava do poder público municipal para atender as suas demandas e trabalhar em favor da localidade, atendendo as questões relacionadas ao agronegócio, surgindo assim as: “[...] famílias de municípios do agronegócio” (SILVA, 2009, p. 88).

Dessa forma, percebe-se que tanto em Mato Grosso, quanto no Paraná, os fatores envolvidos na criação de novos municípios se relacionam principalmente a questões políticas e econômicas, aliada à jurídica, que favoreceu o processo por meio da imposição de regras pouco restritivas de emancipação. Alves (2006) e Tomio (2005) também possuem um posicionamento parecido com o dos autores citados anteriormente em relação a esta questão. Além disso, ambos realizam uma contextualização do processo de criação de novas municipalidades ao longo da história do Brasil.

Alves (2006), analisando questões mais gerais da emancipação paranaense, destaca, principalmente, o papel de eleitores, das lideranças locais, dos deputados estaduais e do governador no processo de criação de novos municípios. O autor defende que as novas emancipações estão relacionadas ao uso desses locais para interesses políticos particulares e melhorias locais em infraestrutura e políticas sociais. Além disso, afirma que o contexto institucional favoreceu as emancipações, ideia defendida também por Tomio (2005) que, ao analisar as emancipações gaúchas, coloca que o arranjo institucional teve um papel importante na criação de novas municipalidades e que os fatores políticos institucionais são os responsáveis pelas emancipações pós Constituição de 1988.

Tanto Alves (2006), como Tomio (2005) também colocam que as demandas de verbas, principalmente do FPM e a responsabilidade estadual de criar regras para a emancipação de novos municípios estimularam o surgimento de novas municipalidades. Além disso, destacam principalmente o papel dos deputados estaduais nas emancipações, pois estes teoricamente não teriam nenhum benefício ao se envolver na causa da criação de novos municípios, mas que, por fim, compreende-se que o motivo principal da participação efetiva no processo estava relacionado a questão eleitoral.

Já Baltar e Baltar (2018), referindo-se as emancipações no Paraná por meio de dados mais quantitativos, como aspectos demográficos e urbanos e o uso de índices de qualidade de vida, buscam justificar que a participação popular, a 
descentralização e a criação de municípios pequenos, principalmente, possuem forte influência nos processos emancipacionistas. Os autores, tratando sobre 0 desenvolvimento dos novos municípios, colocam que devem ser analisados mais fatores do que somente os políticos, econômicos e jurídicos e que nem a utilização do Índice de Desenvolvimento Humano Municipal (IDH-M) seria suficiente para compreender se as emancipações foram benéficas ou não.

\section{Considerações finais}

Após 30 anos de Constituição Federal de 1988, é necessário fazer um balanço da criação de novos municípios, de seus contextos de criação e desdobramentos políticos e econômicos. Assim, a partir do exposto nessa revisão de literatura sobre o processo de criação de municípios, é possível perceber que o contexto que estimulou o boom de novas municipalidades está atrelado a Constituição Federal de 1988, a qual deu o "pontapé inicial" que favoreceu a criação de novas municipalidades. Vinculado a isso, as leis estaduais que determinavam os parâmetros da criação de municípios junto com a ação da população e dos políticos locais e/ou estaduais, além dos fatores econômicos, foram os determinantes da explosão de novas municipalidades que ocorreu pós 1988.

Durante essa revisão de literatura, fica claro que houve diferentes questões e interesses envolvidos nesse processo e que esses fatores possuem similaridades entre si, tanto na escala estadual quanto na escala federal. Chega-se a essa afirmação por meio do alinhamento dos resultados em torno das questões políticas, econômicas e jurídicas da criação de novos municípios, expostos como os motivos que levaram a fragmentação dos municípios.

Desse modo, as questões políticas estão relacionadas a forte presença dos deputados estaduais e de lideranças locais envolvidos no processo. As questões econômicas, estão tareladas ao repasse de verbas como o FPM e o ICMS, que significaram um alento na sobrevivência municipal, pois sozinhos, grande parte dos municípios não teria como arrecadar fundos para investimentos. E jurídicas, pelos requisitos impostos pelas leis estaduais que serviram de base para a criação de novas municipalidades.

Também, podemos concluir que a emancipação é um processo resultante da busca por mais participação e visibilidade da região no contexto político brasileiro. Além disso, a criação de novos municípios foi muito estimulada por meio da ideia de que seria um ente autônomo, mas de acordo com o que foi exposto ao longo desse 
trabalho, essa autonomia é restrita. Ou seja, comparado a esfera estadual e federal, o município não é totalmente autônomo, pois necessita seguir regras estabelecidas pelos entes superiores. E em relação à economia, principalmente os municípios pequenos que não tem a possibilidade de arrecadação de verbas que possam suprir as necessidades locais, tornam-se dependentes do repasse de quantias pelo estado e pela federação. Assim, coloca que a autonomia municipal é limitada. O município sempre será sujeito a uma lei, norma, verba que tira a sua autonomia absoluta.

Somado a isto, se salienta que o município é um território governado por vereadores e prefeito, eleitos pela população pertencente a esse ente administrativo. Nesse território, há interesses particulares e/ou coletivos envolvidos e relacionados, tornando-se um lugar onde são expressas relações de poder. Mediante a isso, o município passa a ser um importante local para visibilidade e aquisição, por exemplo, de benefícios pessoais e/ou coletivos.

Portanto, conclui-se que a criação de novos municípios pós Constituição Federal de 1988 foi um processo que gerou uma vasta fragmentação territorial atrelado a diversas questões discutidas na atualidade, mas sem uma conclusão específica com base na literatura que dialoga sobre o tema. Isto é: os processos emancipatórios de diferentes regiões foram movidos por interesses parecidos, mas não existe uma definição do que levou a elaboração do parágrafo $4^{\circ}$ do Art. 18 da Constituição Federal na literatura sobre esse tema. Dessa forma, o entendimento sobre o processo de criação de novos municípios continua obscuro. Tanto é que a impossibilidade de criação de novos municípios ainda se encontra baseada na Emenda Constitucional no 15, de 1996, que exige que a criação de novas municipalidades deve ser realizada durante um período estabelecido por lei complementar federal, que desde a promulgação da Emenda, até o presente momento, não existiu.

\section{REFERÊNCIAS}

ALVES, Alessandro Cavassin. O processo de criação de municípios no Paraná: as instituições e a relação entre executivo. Revista Paranaense De Desenvolvimento, Curitiba, n. 111, p. 47-71, jul./dez. 2006. Disponível em: http://www.ipardes.pr.gov.br/ojs/index.php/revistaparanaense/article/view/61. Acesso em: 24 mai. 2019.

BALTAR, Cláudia; Ronaldo, BALTAR. Debatendo a criação de municípios na contemporaneidade: considerações a partir da urbanização e da participação dos pequenos municípios no Brasil e no Paraná. Revista Geografia e Ordenamento do Território [Online], n. 14, p. 71-107, set. 2018. Disponível em:

https://www.academia.edu/38014530/Debatendo_a_criação_de_municípios_na_contempora 
neidade_considerações_a_partir_da_urbanização_e_da_participação_dos_pequenos_muni cípios_no_Brasil_e_no_Paraná. Ācesso em: 24 mai. 2019.

BRASIL. [Constituição (1967)]. Emenda Constitucional no 1, de 17 de outubro de 1969. Edita o novo texto da Constituição Federal de 24 de janeiro de 1967. Disponível em: http://www.planalto.gov.br/ccivil_03/Constituicao/Emendas/Emc_anterior1988/emc0169.htm. Acesso em: 28 out. 2018.

BRASIL. [Constituição (1988)]. Constituição da República Federativa do Brasil. Disponível em: http://www.planalto.gov.br/ccivil_03/Constituicao/Constituicao.htm. Acesso em: 28 out. 2018.

CASTRO, Iná Elias. Geografia e política: território, escalas de ação e instituições. Rio de Janeiro: Bertrand Brasil, 2005. 304 p.

CIGOLINI, Adilar Antonio. Análise da literatura explicativa sobre o processo contemporâneo da criação de municípios no Brasil. Revista de Estudios Brasileños, v. 4, n. 6, p. 95-107, 2017. Disponível em: https://revistas.usal.es/index.php/2386-

4540/article/viewFile/reb20174695107/19258. Acesso em: 05 jun. 2020.

CIGOLINI, Adilar Antonio. Território e criação de municípios: o significado teórico-político da compartimentação do espaço. Revista Ra'e Ga, Curitiba, n. 25, p. 111-133, 2012.

Disponível em: https://revistas.ufpr.br/raega/article/view/28006. Acesso em: 24 mai. 2019.

CIGOLINI, Adilar Antonio. Território e fragmentação: análise do processo recente de criação de municípios no Paraná. Revista Ra'e Ga, Curitiba, n. 6, p. 47-66, 2001. Disponível em: https://revistas.ufpr.br/raega/article/view/18315/11878. Acesso em: 24 mai. 2019.

FERNANDES, Antônio Sérgio Araújo; ARAÚJO, Suely Mara Vaz Guimarães. A criação de municípios e a formalização de regiões metropolitanas: os desafios da coordenação federativa. Revista Brasileira de Gestão Urbana [Online], v. 7, n. 3, p. 295-309, set./dez. 2015. Disponível em: http://www.scielo.br/scielo.php?pid=S2175-

33692015000300295\&script=sci_abstract\&tlng=pt. Acesso em: 24 mai. 2019.

FERRARI, Sérgio. Criação de municípios e debate científico: entre mitos e métodos. Revista de Informação Legislativa, Brasília, v. 53, n. 211, p. 55-80, jul./set. 2016. Disponível em: http://www2.senado.leg.br/bdsf/handle/id/525419. Acesso em: 09 jul. 2019.

MATSUMOTO, Carlos Eduardo Higa; FRANCHINI, Matías; MAUAD, Ana Carolina Evangelista. Município: Palco da Vida - A história do municipalismo. Brasília: CNM, 2012. 264 p. Disponível em:

https://www.researchgate.net/publication/334576322_Municipio_Palco_da_Vida_A_historia_ do_municipalismo_brasileiro_Volume_1. Acesso em: 08 nov. 2019.

MONTORO, Eugênio Augusto Franco. O município no desenvolvimento brasileiro. Revista de Administração de Empresas, São Paulo, v.16, n. 5, p. 29-32, set./out. 1976. Disponível em: http://www.scielo.br/scielo.php?script=sci_arttext\&pid=S0034-75901976000500003. Acesso em: 09 jul. 2019.

NUNES, Marcos Antônio. Criação de municípios no Brasil: motivações, vantagens e desvantagens. Revista Espinhaço, v. 6, n. 1, p. 11-20, 2017. Disponível em: http://www.revistaespinhaco.com/index.php/journal/article/view/149. Acesso em: 24 mai. 2019.

SANTOS, Milton. A Natureza do Espaço: Técnica e Tempo. Razão e Emoção. 2. Ed. São Paulo: Hucitec, 1997. 308 p. 
SILVA, Silvana Cristina. A criação de municípios no front e a formação da elite do agronegócio: faces do uso do território brasileiro. Revista Geosul, Florianópolis, v. 24, n. 48, p. 85-101, jul./dez. 2009. Disponível em:

https://periodicos.ufsc.br/index.php/geosul/article/viewFile/21775230.2009v24n48p85/12283. Acesso em: 24 mai. 2019.

SOUZA, Fernando Mendes de; CIGOLINI, Adilar Antônio. Criação de municípios e conflitos institucionais no Brasil. Revista Terr@ Plural, Ponta Grossa, v.13, n.3, p. 42-54, set./dez. 2019. Disponível em:

https://www.revistas2.uepg.br/index.php/tp/article/view/12746/209209212627. Acesso em: 05 jun. 2020.

TOMIO, Fabricio Ricardo de Limas. A criação de Municípios após a Constituição de 1988. Revista Brasileira de Ciências Sociais, v. 17, n. 48, p. 61-89, fev. 2002. Disponível em: http://www.scielo.br/scielo.php?script=sci_arttext\&pid=S0102-69092002000100006. Acesso em: 24 mai. 2019.

TOMIO, Fabricio Ricardo de Limas. Federalismo, municípios e decisões legislativas: a criação de municípios no Rio Grande do Sul. Revista de Sociologia e Política [Online], Curitiba, n. 24, p. 123-148, jun. 2005. Disponível em:

http://www.scielo.br/scielo.php?pid=S0104-

44782005000100009\&script=sci_abstract\&tIng=pt. Acesso em: 24 mai. 2019.

\section{NOTAS DE AUTOR}

\section{CONTRIBUIÇÃO DE AUTORIA}

Nathália Bonow - Concepção, Coleta de dados, Análise de dados, Elaboração do manuscrito, revisão e aprovação da versão final do trabalho.

Robinson Santos Pinheiro - Elaboração do manuscrito, Participação ativa da discussão dos resultados, Revisão e aprovação da versão final do trabalho.

\section{FINANCIAMENTO}

Não se aplica.

\section{CONSENTIMENTO DE USO DE IMAGEM}

Não se aplica.

\section{APROVAÇÃO DE COMITÊ DE ÉTICA EM PESQUISA}

Não se aplica.

\section{CONFLITO DE INTERESSES}

Não se aplica.

\section{LICENÇA DE USO}

Este artigo está licenciado sob a Licença Creative Commons CC-BY. Com essa licença você pode compartilhar, adaptar, criar para qualquer fim, desde que atribua a autoria da obra.

\section{HISTÓRICO}

Recebido em: 08-11-2019

Aprovado em: 09-06-2020 